Journal Universitas Muhammadiyah Gresik Engineering, Social Science, and Health International Conference (UMGESHIC)

UMGCINMATIC : $1^{\text {st }}$ Rethinking Education during Covid-19 Era: Challange and Innovation

\title{
ANALYSIS OF TEACHERS' PERSPECTIVE TOWARDS YOUTUBE AS A LEARNING TOOL TO YOUNG LEARNERS' VOCABULARY DEVELOPMENT ON VIRTUAL LEARNING
}

\author{
Salsabilah Arifah ${ }^{1}$, Prativi Khilyatul Auliya ${ }^{2}$ \\ ${ }^{1,2}$ University of Muhammadiyah Gresik \\ Email : Salsabilah_180403@umg.ac.id, Prativi.auliya@umg.ac.id
}

\begin{abstract}
This article aims to investigate teachers' perspective towards using YouTube as a learning tool on young learners' vocabulary development through virtual learning. The researchers used a qualitative approach with online questionnaire and online interview as the instrument. There were seven teachers who participated in this research, the data was collected and triangulated to multiple sources such as questionnaire surveys, and semi-structured informal interviews through online meetings. The result of this research shows that using YouTube as a learning tool on young learners' vocabulary development during the virtual learning can motivate teachers to teach the young learners' vocabulary development using a variety of different learning tools. Video clips on YouTube in virtual classrooms since it is practical in time and money. It is recommended to use YouTube as a learning tool, because it can simplify the lesso since it has audio-visual effects featured. It is fresh, practical, interesting, informative and also more flexible in time and distances learning tool, especially during this Covid-19 pandemic.
\end{abstract}

Keywords: Virtual Learning, YouTube, Young Learner, Vocabulary Development.

\section{INTRODUCTION}

Virtual learning has already been an increasingly popular and useful medium for the student to hold an education process during the Covid-19 pandemic. It has increasingly become a new way of learning for students all around the world, and it includes the young learner in Thai. Virtual learning is designed to extend educational experiences.[1] In virtual learning environments, students can access any educational resources and interact in different ways from traditional classrooms. The previous study investigates classes where computers can be utilized, and also appears the defiance that faces teachers and educators regarding this application.[2] and also virtual learning can be defined as an optional learning that can functionally and effectively occur in the absence of traditional classroom environments. Virtual learning requires computer software, and the Internet. Because the characteristics of virtual learning are distance and internet 
connection, teachers are also needed in virtual learning in order to guide and provide clear instruction for their students. Virtual learning is a learning process that uses technology such as devices and the internet connections as well as the electronic learning materials which are interactive and downloadable.[3] Virtual learning also helps the teachers to communicate with students and parents about the student's progress, as these learning management systems are very helpful for them.

Virtual learning also can overcome the students' boring matter, interest, and bring them to the new learning environment if the teachers can be creative to use technology-based learning to assist them while teaching in the virtual learning process such as YouTube. The previous researchers have concluded that YouTube is a necessary tool in classrooms as it appeals to the student attention and involves their mentality and creativity.[2] It also can assist teachers in the learning materials. YouTube also can lead the students' happiness element into classes, through meeting the interests of students using some of the technology-based internet.[2] The interest in the learning process has a high impact on the educational process, especially when handling big classes. So, YouTube could have a high potential for improving the learning skills of students. YouTube is an online video repository, that was found in February 2005 by three former employees of the e-Commerce Business PayPal, in which users could upload, publish, and watch videos by streaming. Everyone can download, view, and share video clips on a wide variety of content. Such contents include movie clips, TV shows, music videos and video blogs. [2] In the previous study has investigated how effective YouTube is as a learning tool in the educational process and how it is beneficial for language teachers to enhance the skills of students.[4] It turns out that YouTube brings the fun element into classes, which thereby meet the interests. YouTube videos can help the students to guess the meaning of unfamiliar words, help students improve their speaking skills, and prevent students from going astray while speaking and listening to the videos.[5]

Using YouTube as a learning tool to learn in school has so many barriers and challenges. This could influence teachers' perceptions and confidence. Using YouTube as a tool in the classroom has been beneficial both for the teacher and learner. It has Similarity when the teacher uses an interactive whiteboard in teaching and learning through an e-Learning classroom. Also, the virtual learning environment has a positive effect on learners' learning process.[2] It can be concluded that virtual learning has a positive effect on the learner. But, Using YouTube as a learning tool to learn in school has so many barriers and challenges. This could influence teachers' perceptions and confidence. A lot of research that has been done based on the students' perspective, but there is no research that has been done from teachers' perspective.

So, here in this study the researcher decided to investigate this study from the teachers' perspective on how the teachers' experiencing and feels with using YouTube as a learning tool in the learning process for the young learners to student young learners' vocabulary through virtual learning. This paper focuses on the teachers' perspective on how YouTube videos can be used as a learning tool to develop English young learners' vocabulary in Loei, Thailand. 


\section{THEORETICAL FRAMEWORK}

\section{a. YouTube as a tool on Young Learners Vocabulary Development}

Vocabulary can be defined as some words of a language, it is including a single item and phrases or chunks from several words which convey a particular meaning, the way individual words do. Vocabulary also could represent one of the most important skills that are necessary for teaching and learning a foreign language process. Through vocabulary, all the other skills which are; reading, writing, speaking, and listening could developed.[6] The main aspect of language skills is vocabulary which can support students' ability to the four skills in a language (speaking, listening, reading, and writing). But there is one of the principles in learning a language that is vocabulary.[7] It is also strengthened by the statement that says "Without grammar very little can be conveyed, without vocabulary, nothing can be conveyed".[8] Thus it can be interpreted that, as hard as you learn the grammar, your English will not develop if you do not learn or improve the vocabulary. Similarity to the research that outline "Vocabulary can be defined, roughly, as the words we teach in the foreign language. However, vocabulary may be more than just a single word: for example, a piece of chalk and mother-in-law, which are made up of two or three words but express a single idea".[9]

Because of some of the research, it is very important to learn a new language from the basics and it is very good to start at a young age. Young learners are very active and respond well to praise, they are also very interested in learning-based playing games.[10] Young learners could be very interested in learning by imitating what they listen and watch. In the learning process, they also could find it very hard to focus on one thing. In this research, the researcher conducted this study to know the young learner's English vocabulary development through YouTube as the learning tool. Since YouTube is effective in online learning process.[11]

\section{b. The Use of YouTube in the Virtual Learning}

One of the online media platforms that can be used in the learning process is YouTube.[11] YouTube is a free web based service that contains short contents about specific concepts. [12] YouTube has the potential to be an useful educational tool that offers endless opportunities for formal and informal education for the student centered language learning approaches. [13] Based on the previous study, the researcher has found the use of video clips from YouTube to aid student comprehension.[14] The Preparation for using YouTube activity, it's requires the teacher to create a short narrative text based on the contents material of the chosen YouTube video before the lesson is started. The lesson plan should follow all the stages such as; preparation stage, dictation stage, reconstruction stage, and then closing stage.

\section{1) Preparation stage}

In this stage, all the hardware and software components should be available during the process, the screen, laptop, and the internet connection has to be connected. 
Teachers should prepare video clips that provide some educational content and it is fun to enjoy.

\section{2) Dictation stage}

Teachers have to illustrate the topic that the young learner will learn for the day, teachers can use some illustration video clips if it's necessary. YouTube videos present alternative viewpoints to develop the student's ability to reach some vocabulary development. And also, videos that are served by the teacher have to be a stimulus for their student learning activities.

\section{3) Reconstruction stage}

While playing the video, the teacher can ask students for their reaction in an open discussion, direct them to answer specific questions collaboratively, or ask specific questions about the content presented. YouTube clips that the teacher used should get the student's attention through inserting sound clips of comedy or inspiring and motivating videos to the class while covering any particular topic and also should be entered into collaborative learning exercises to student vocabulary development. The teacher can assign some examples of a new vocabulary that they learn that day. YouTube videos should motivate and inspire students through a colorful video content may make a huge difference in their moods, motivation, and attitude.

\section{4) Closing Stage}

In this stage, the teachers should review all the material that they give to their students in the class, and try to ask students to conclude it. After that, the teacher can give the students a task if it is necessary. Then the teacher can end the class.

\section{c. The Use of YouTube for Young Learners Vocabulary}

There are many media platforms which can be used in teaching vocabulary to young learners. In this research, the researcher used teachers' perspective on using YouTube to teach young learner vocabulary. The previous study has found that using YouTube has significant improvement for the students' vocabulary achievement.[15] The enjoyable and entertaining atmosphere that created by the use of YouTube could motivated the students to learn.[16] Most young learners at an English course were engaged during the implementation of the video on YouTube in teaching vocabulary.[17] With the evolution of the Web YouTube will provide a broader spectrum of functionality for instance using exact word and phrase search that will proof to be especially useful for language learning.[13] YouTube in the classroom could develop vocabulary, make learning fun and interesting, and also motivate learners. YouTube also offered statistically significant effects on the students' vocabulary acquisition.[18] YouTube videos can also be utilized as realia to stimulate cultural lessons, and promote authentic vocabulary development.[19] Since YouTube is an online platform that contain a huge amount of creative content maker, the student can use YouTube as a new tool to improve their vocabulary. 


\section{RESEARCH METHOD}

The approach used in this research is a qualitative approach with a survey method. This is an analytical study based on the teacher's perspective on the vocabulary development of young learners. The type of research in this study is qualitative-descriptive. This research was held for one semester. In this study the sample was taken with a random sampling method. Respondents in this study were selected through personal contact.

To explore the teacher's perspective towards student vocabulary development Using YouTube as a tool on Virtual Learning for educational purposes without unnecessary danger of virus infection, the present study is conducted through questionnaire online survey and online interview as the instrument. Based on the purpose of the study, 7 active English teachers who taught at their Thai schools willingly participated in the study survey to get more in-depth information about the values, experiences, and attitudes towards using YouTube education for the development of their students' vocabulary. These teachers were born and raised in Thailand. The average age of teachers is 30.7 with age ranges ranging from 20-43. Two male and five female teachers. The Data was collected and triangulated to multiple sources such as questionnaire surveys, and semi-structured informal interviews through online meetings. For this study, the questionnaire survey served as the first source of information. The data that has been collected is the data about their experience when using YouTube on their students and their perception of how it affects their academic involvement in the context of the development of their student vocabulary. After that, informal online interviews are conducted with each of the seven teachers. Informal interviews (online chat and voice notes) are conducted as an additional data collection tool, allowing teachers to share their stories in a more relaxed and comfortable environment.

The researchers of the present study have developed a ten-item questionnaire questions applied to the elementary teacher in Loei, Thailand. Participants respond to each item as a linear scale number from 1-5. For number 1, it is pointed as strongly disagreeing, while for number 3 is for the Neutral, and number 5 for strongly agreeing with the statement. The researcher confirmed the statement with a semi-formal interview that was held by the researcher by online meeting and a LINE Messenger Application. The sample is limited to the teacher of the preliminary because in the school that the researcher does the research is on the preliminary level. The researchers conducted and applied the questionnaire electronically using the Google form that is shared through a link in the LINE message application to reach all the teachers who participate in this study. A vote was structured and distributed to 8 teachers but only 7 teachers responded to the questionnaire. Thus, the study sample considered the male and female teachers who answered the closed survey to evaluate the result of their perspective on how effective YouTube is as a learning tool, is it can be used to improve the student vocabulary. The researchers constructed the items of the poll based on the fact that YouTube as a learning tool can be used to improve young learners' vocabulary and it is influential for the educational environment and language virtual learning for the young learners. Besides, they are supported and highlighted by others. 


\section{RESULTS AND DISCUSSION}

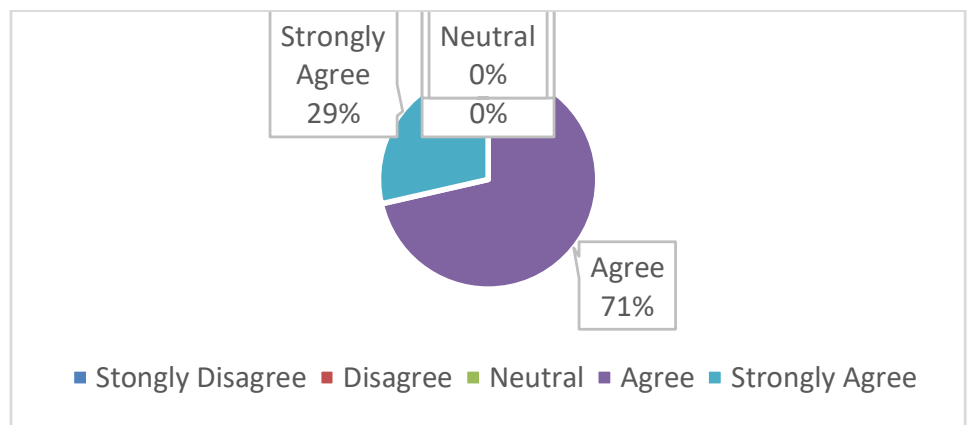

Chart.1 Teaching young learners through YouTube clips and content videos is easy, practical, and the students are enjoying the learning process when the teacher uses YouTube in the virtual classroom chart.

The responses from the teachers to item number one, "Teaching young learners through YouTube clips and content videos is easy, practical, and the students are enjoying the learning process when the teacher uses YouTube in the virtual classroom." show that $71 \%$ of them agree and about $29 \%$ of them strongly agree to this statement. It has been confirmed to the teachers that using YouTube is practical they also mentioned that their students enjoy learning through YouTube. It is quite interesting as they have so much fun while experiencing it. And also, their students are enjoying the learning process more when their teacher uses YouTube as their learning tool since it has audio and visual effects and also, they can choose a variety of videos from unlimited sources. There are some findings in a previous study that found that $43 \%$ of the students agree that the materials are explained on video adequately, and the students fully comprehend them. [4] And also, some of the previous study supports this view through his interviews with language students. He concluded that the majority of his sample members feel happy and satisfied while watching YouTube videos. [20]

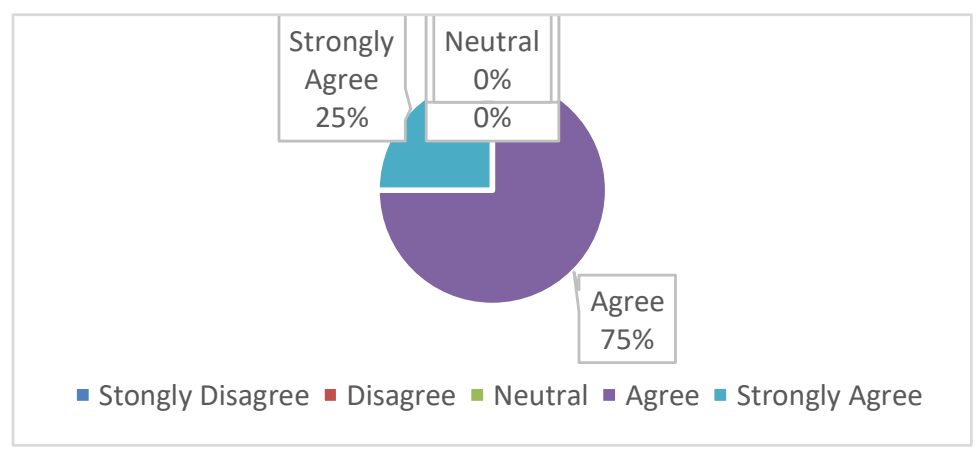

Chart.2 Mostly my students understand the material presented on YouTube videos properly and they are more active in the learning process chart. 
In the item number two, "Mostly my students understand the material presented on YouTube videos properly and they are more active in the learning process." The result showed that $75 \%$ of teachers agree, and there are also $25 \%$ of them strongly agree with this statement. The materials that the teachers use on YouTube are understandable and mostly their students are more active in the learning process and their students understand the content learned from the tutorials uploaded to YouTube. It is confirmed with the teachers, they said that "as long as the internet connection is good enough the student will easily understand the material presented and be more active during the process." In contrast to the result from the previous study, $43 \%$ of students agree that the materials are explained on video adequately, and the students are fully comprehend them. Only $36 \%$ are neutral to this, and $21 \%$ disagree on the probability of gaining a complete understanding of the materials.[4]

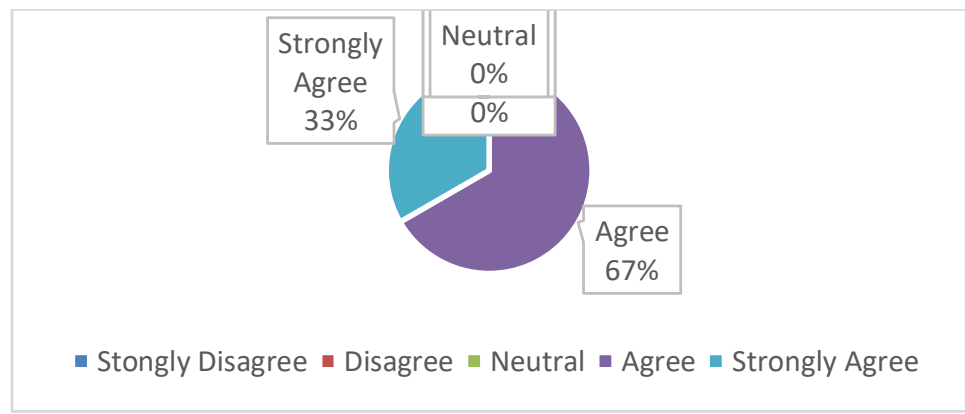

Chart.3 The teachers must use YouTube as a learning tool not to replace the role of the teacher in the virtual classroom chart.

For item number three, "The teachers must use YouTube as a learning tool not to replace the role of the teacher in the virtual classroom." teachers' responses show that $67 \%$ agree and about $33 \%$ strongly agree with this statement. Within this statement, the present study found that the possibility of using videos instead of the teacher in classes is not high enough to replace the role. Since the student still has to ask the teacher if they have a question regarding their understanding of the material presented or not, and only watching a video on YouTube cannot give the answer to the student, especially for the young learners they tend to have unlimited curiosity and teachers know the subject material and give good feedback. The findings of the present study show a considerable interest in using YouTube as a learning tool in the virtual classroom. The previous study assures that technology can play a crucial role in improving the understanding of the students and shows that learners are eager to have technology like YouTube in the classroom to be more comfortable.[20] The point here is that mostly all of the students are enjoying the virtual learning process using YouTube. As long as there is a brief instruction, creative and interesting material content from the teacher, the student will follow the teacher's instruction without any trouble. It shows that teachers must employ YouTube videos as a tool for learning. 


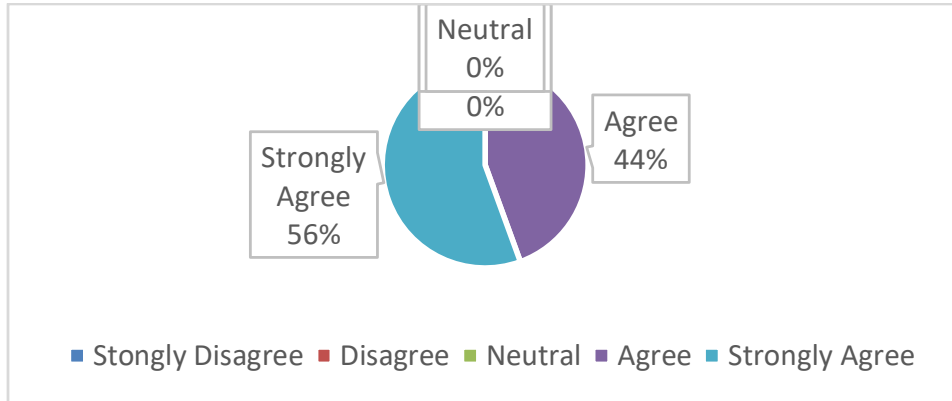

Chart.4 The teacher can use YouTube to assign student vocabulary assignments in a virtual learning chart.

For item number four, "The teacher can use YouTube to assign student vocabulary assignments in a virtual learning." teachers' responses show that $44 \%$ agree with the change and $56 \%$ strongly agree with this statement. The point here is that teachers can use YouTube not just only to present material but also can be used as a tool for their student assignment. It has been confirmed to the teachers that sometimes they ask their students to upload their assignment as a video on YouTube since it is not possible to submit their assignment directly during the Covid-19 pandemic.

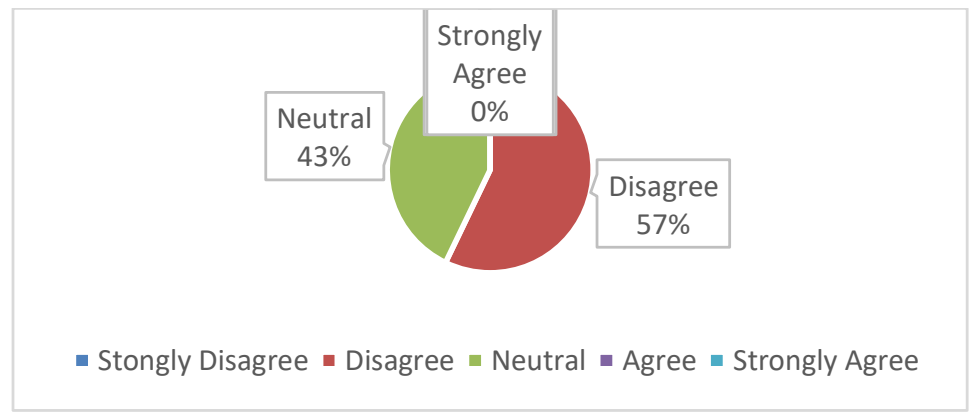

Chart.5 using YouTube takes a lot of money and time chart.

For item number five, "using YouTube takes a lot of money and time." $43 \%$ of the participants find it to be neutral, and about 57\% disagree with this statement. It has been confirmed to the teachers that using YouTube is not really that expensive, since YouTube itself is free. But some of the components need money, for the example is the internet. 


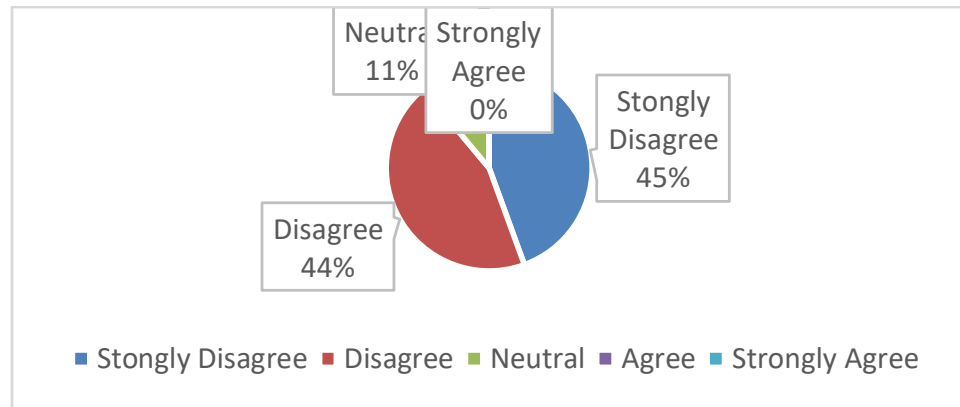

Chart.6 There are many disadvantages to using YouTube Videos clips as a learning tool in the virtual learning process chart.

In Item number six, "There are many disadvantages to using YouTube Videos clips as a learning tool in the virtual learning process." shows that $45 \%$ strongly disagree, $44 \%$ disagree, and $11 \%$ are neutral with this statement. This statement has been confirmed by the teachers, they said that they disagree that YouTube has more disadvantages as a learning tool since it can be accessed by anyone, everywhere, anytime, and unlimitedly as long as the user has a good internet connection and the device to use it. But, the teachers also state that they do not always use YouTube as their learning tool to improve student vocabulary. They only use YouTube if the student has low interest in the usual learning process shows that YouTube can be used as a learning tool for the young learners since it has entertaining and educational factors on it.



Chart.7 From YouTube videos clips content, teachers can improve young English learners' vocabulary development in the virtual learning process chart.

Item number seven, "From YouTube videos clips content, teachers can improve young English learners' vocabulary development in the virtual learning process." $100 \%$ teachers agree with this statement. In this study, teachers find that YouTube videos are significant in improving students' vocabulary. It has confirmed to the teacher that surprisingly their student vocabulary is improving through the video clips from YouTube. Unlike the previous study, the result displays that $75 \%$ of students find YouTube videos significant in improving these two aspects of language. Only $11 \%$ do not agree, and $14 \%$ are neutral to the statement that says YouTube videos are vital in developing grammatical patterns and building vocabulary.[4] YouTube videos can simplify 
lessons since they have audio and digital effects and make them more realistic and understandable.[20] In addition, he states that the audio-visual effects featured in YouTube videos can help learners to grasp the hidden meanings of some references and idioms in the English language and sources that are available in the library.

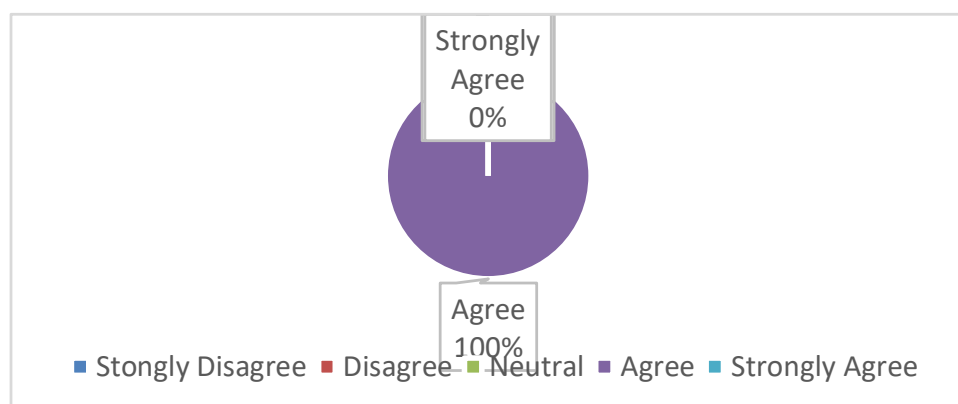

Chart.8 YouTube videos clips content can enhance student language skills, especially in listening and speaking chart.

As for item number eight, "YouTube videos clips content can enhance student language skills, especially in listening and speaking." $100 \%$ of the teachers agree with this statement. Not only for improving student vocabulary, YouTube also can be used to improve other students' language skills. One of the teachers said that if the teacher can use the video clips from YouTube properly and find some good quality on the video, by watching from videos on YouTube can improve their language skills, speaking and listening in particular but of course it should be in sync with practice. reviews that YouTube is a useful tool that can build the knowledge of learners and help them improve their English fluency. Also, watching YouTube videos can help learners to communicate and experience events in the various videos.

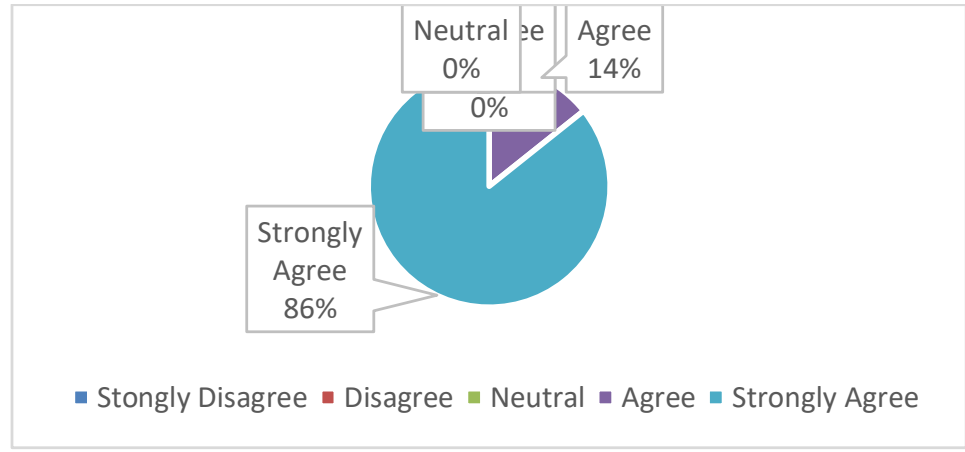

Chart.9 I found myself feeling motivated to teach the student when I used the material on YouTube chart.

As for item number nine, "I found myself feeling motivated to teach the student when I used the material on YouTube chart" $14 \%$ of the teachers agree and $86 \%$ is strongly agree with 
this statement. Not only for the student, the benefits of using YouTube also could affect the teacher. It has been confirmed by the teachers that they feel more active and motivated when they use YouTube in the process before and after the learning process. One of them said that because on YouTube they have seen a lot of professional video clips. YouTube is a useful tool that can build the knowledge of both learners and teachers. It could help them improve their English fluency. And help them to communicate, participate and experience events in the various videos.

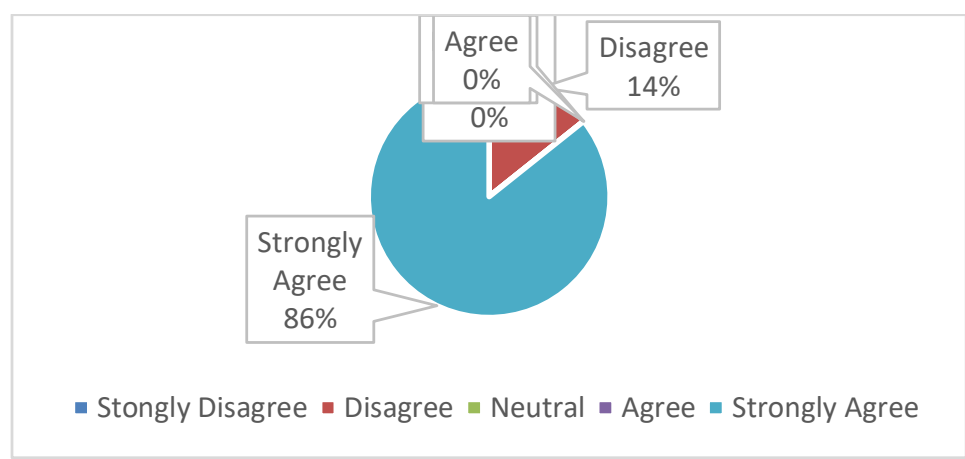

Chart.10 I recommend to others teachers to teach their student using YouTube chart.

As for item number ten, "I recommend to other teachers to teach their students using YouTube" $14 \%$ of the teachers disagree and $86 \%$ is strongly agree with this statement. It has been confirmed to the teacher that they will recommend it to other teachers to use YouTube if the teacher can use YouTube effectively. They won't recommend it if they think that the teacher that they will recommend can't use technology because it will make them confused.

The point of the researchers through this study is to analyze YouTube as a learning tool from teachers' perspective for the young learners' vocabulary development in the virtual learning process. The questionnaire items find out the positive feelings and experiences from both the teachers and the students. Thus, these findings should be taken when applying technology to classrooms to enhance the teaching-learning virtually process. Recommendations and suggestions is of priority to this research as it is a real attempt to lessen the challenges. As the results display, teachers find that using YouTube as a learning tool during the virtual learning is fresh, practical, interesting, informative and also more flexible in time and distances.

\section{CONCLUSION}


To increase the students' understanding materials, and vocabulary development, teachers should take YouTube videos seriously as an educational tool since the teacher can choose the proper videos and time length and they can play the videos indefinitely. Teachers have a strong motivation for using YouTube videos in virtual classrooms since it is practical in time and money. To the extent of that statement, they confirm that it is the best option for a learning tool in virtual learning. Since YouTube is an online platform that can be used by anyone, everywhere, anytime, and unlimitedly as long as the user has a good internet connection and the device to use it. Besides, teachers do believe that YouTube videos can enhance their students' language skills and aspects, especially in speaking and listening.

Teachers find that using YouTube is the best medium to the virtual educational process as it offers all the advantages of having more beneficial and exciting teaching experience and it is enjoyable for both teachers and students. It can be a good learning tool in virtual learning since it can be accessed by anyone, everywhere, and anytime especially during this Covid-19 pandemic. YouTube videos can help students to approach new vocabulary through the authentic material presented in videos clips. But still YouTube cannot replace the role of the teacher in the learning process because the students still need to be guided to use YouTube as their learning tools. Thus, YouTube videos are vital for the educational process, and further studies should be more focused on improving student learning interest during the Covid-19 pandemic at different levels.

\section{REFERENCES}

[1] D. Meyer, "Virtual Learning," Elmhurst University, 2020. https://www.elmhurst.edu/blog/virtual-learning/.

[2] S. H. H. Pratama, R. A. Arifin, and A. W. S. Widianingsih, "The Use of Youtube as a Learning Tool in Teaching Listening Skill,” Int. J. Glob. Oper. Res., vol. 1, no. 3, pp. 123129, Aug. 2020, doi: 10.47194/ijgor.v1i3.50.

[3] Kawinkoonlasate and Pongpatchara, "Online Language Learning for Thai EFL Learners: An Analysis of Effective Alternative Learning Methods in Response to the Covid-19 Outbreak," Can. Cent. Sci. Educ., vol. 15-26, 2020.

[4] N. Fadhil Abbas and T. Ali Qassim, "Investigating the Effectiveness of YouTube as a Learning Tool among EFL Students at Baghdad University," Arab World English J., vol. 6, pp. 344-356, Jul. 2020, doi: 10.24093/awej/call6.23.

[5] Fahad Saud Albahlal, "The Impact of YouTube on Improving Secondary School Students' Speaking Skills: English Language Teachers' Perspectives,” J. Appl. Linguist. Lang. Res., vol. 6, no. 2, pp. 1-17, 2019, [Online]. Available: http://www.jallr.com/ jallrir/index.php/JALLR/article/view/971/pdf971. 
[6] S. Knight, "The Effects of comprehension and vocabulary acquisition for student of different verbal abilities," Mod. Lang. J., vol. 78, no. 3, pp. 285-299, 1994.

[7] Rahmadhani, P. A., "Techniques in teaching vocabulary to young learners at LIA english course,” TELL-US J., vol. 1, no. 2, pp. 1-8, 2015.

[8] Z. Qian, "How to Teach Vocabulary in Chunks," 2015, p. 13, doi: 10.2991/jisem15.2015.43.

[9] S. Syafrizal, "The implementation of vocabulary building strategy in teaching English vocabulary to young learners," J. English Lang. Teach., vol. 5, no. 1, pp. 40-48, 2018, [Online]. Available: http://ojs.ikipmataram.ac.id/index.php/joelt.

[10] Farnawiyah, "Characteristics of Young Learners," 2010. https://farwaniya03.tripod.com/id6.html (accessed Oct. 28, 2021).

[11] R. Rahmatika, M. Yusuf, and L. Agung, "The Effectiveness of Youtube as an Online Learning Media," J. Educ. Technol., vol. 5, no. 1, p. 152, Apr. 2021, doi: 10.23887/jet.v5i1.33628.

[12] Y. Chtouki, H. Harroud, M. Khalidi, and S. Bennani, "The impact of YouTube videos on the student's learning," in 2012 International Conference on Information Technology Based Higher Education and Training (ITHET), Jun. 2012, pp. 1-4, doi: 10.1109/ITHET.2012.6246045.

[13] Ines Brünner, "Using Language Learning Resources on YouTube.," Int. Conf. Lang. Teach., pp. 1-5, 2013, [Online]. Available: https://conference.pixelonline.net/conferences/ICT4LL2013/common/download/Paper_pdf/215-ELE13-FPBruenner-ICT2013.pdf.

[14] A. K. R. Nasution, "YouTube as a Media in English Language Teaching (ELT) Context: Teaching Procedure Text," Utamax J. Ultim. Res. Trends Educ., vol. 1, no. 1, pp. 29-33, Jul. 2019, doi: 10.31849/utamax.v1i1.2788.

[15] R. Kabooha and T. Elyas, "The Effects of YouTube in Multimedia Instruction for Vocabulary Learning: Perceptions of EFL Students and Teachers," English Lang. Teach., vol. 11, no. 2, p. 72, Jan. 2018, doi: 10.5539/elt.v11n2p72.

[16] Huda Omar Alwehaibi, “The Impact Of Using YouTube In EFL Classroom On Enhancing EFL Students' Content Learning,” J. Coll. Teach. Learn., vol. 12, no. 2, pp. 121-126, 2015.

[17] T. C. Hariyono, "TEACHING VOCABULARY TO YOUNG LEARNER USING VIDEO ON YOUTUBE AT ENGLISH COURSE," Lang. Res. Soc., vol. 1, no. 1, May 2020, doi: 10.33021/lrs.v1i1.1038. 
[18] D. Heriyanto, “The Effectiveness of Using Youtube for Vocabulary Mastery," ETERNAL (English Teach. Journal), vol. 6, no. 1, Apr. 2018, doi: 10.26877/eternal.v6i1.2290.

[19] J. Watkins and Michael Wilkins, "Using YouTube in the EFL Classroom," Lang. Educ. Asia, vol. 2, no. 1, pp. 113-119, 2011.

[20] W. A. Almurashi, "The Effective Use of YouTube Videos for Teaching the English Language in Classrooms as Supplementary Material at Taibah University in Alula," Int. J. English Lang. Linguist. Res., vol. 4, no. 3, pp. 32-47, 2016. 